\title{
Multi-objective consideration of earthquake resilience in the built environment: the case of Wenchuan earthquake
}

\author{
Giulia Cerè, Wanqing Zhao, Yacine Rezgui \\ BRE Trust Center for Sustainable Engineering \\ Cardiff University \\ 52 The Parade, CF243AA Cardiff, United Kingdom \\ cereg, zhaow9, rezguiy@cardiff.ac.uk
}

\author{
Robert Parker, Tristram Hales, Brian Hector \\ MacGillivray, Yi Gong \\ Sustainable Places Research Institute \\ Cardiff University \\ 33 Plas Y Parc, CF103BA Cardiff, United Kingdom \\ parkerr, halest, macgillivraybg, gongy2@cardiff.ac.uk
}

\begin{abstract}
The 2008 Wenchuan earthquake is one of the largest and deadliest events of the last century, both in terms of victims and seismically-triggered geo-environmental hazards. The combined effects resulting from the seismic activity of 2008 led to major damages in several domains of the local society, including the built environment and the social component, highlighting the extensive gap related to resilience measures aimed at both prevention and recovery in case of a disruption. Thus, it is imperative for the development of a multi-objective and comprehensive formulation for resilience combining holistically all the diverse facets of a local community. To this regard, this paper presents a wide-spectrum analysis and preliminary findings, being structured in working threads specifically addressed in the context of an ongoing project (REACH). The focus is on the built environment damage analysis following the field work which took place in December 2016 in the Wenchuan territory, involving 3D laser scanning activity of 7 high-risk areas and the related audit and preliminary structural analysis of the damage. As a result, a set of external and internal factors have been identified as possible key causes of the surveyed damages. Of these, external factors mainly relate to environmental and hazardous properties, whereas internal indicators involve structural features as well as building regulations.
\end{abstract}

Keywords-resilience; earthquake; natural hazard; built environment; landslide

\section{INTRODUCTION}

The 2008 Wenchuan earthquake still represents one of the largest and deadliest earthquake events of this century, with over 60,000 earthquake-induced landslides registered [1], [2] and more than 68,858 deaths [3]. Between 2008 and 2012 over 2300 landslides were induced by subsequent aftershocks and rainfall events, representing an over 3-times-higher amount of landslides than the one recorded in the 4 years before the earthquake [4]. The rich dataset resulting from this event consists in one of the largest ever collected [4], allowing fine-scale spatial-temporal data analysis. In the aftermath, the 2013 Lushan earthquake occurred immediately southwest of the previous seismic activity area with similar geologic features that characterized the main event in the Wenchuan County.

The REACH project addresses the above mentioned area given its seismic activity history and the significant amount of data which enable event forecasting and understanding of phenomena mechanisms.

The multi-disciplinary approach of the project intends to develop a fundamental, policy-relevant science aimed to improve earthquake resilience in China, in which the Sendai Framework [5] is recognized as essential for economic development. Earthquake-induced losses are not evenly distributed in space and time, as they are contingent on a hazard chain of main shock, aftershocks, and subsequent climatic events [4]. In particular, high landsliding rates have been observed after earthquakes, creating a persistent hazard that jeopardizes recovery. Besides, adequate mechanistic explanation for post-earthquake landslides and in the ability to forecast potential hazards is not fully and readily available. Key component in determining the impact of landslide and earthquake activities consisted in a specific analysis of the building stock state of the art in order to assess its pre-disruption vulnerability. As a matter of fact, buildings and infrastructures are the foundation of communities and a better understanding of their vulnerability is crucial for future critical damage prevention. The Wenchuan territory involves a geological hostile territory, given the low-resistance soil which can easily lead to secondary geo-environmental hazards in case of heavy rainfalls or major threats like earthquakes, putting at risk infrastructures and buildings at the same time.

The impacts of landslides, and the capacity of communities to absorb and respond to them, will be further shaped by characteristics of the affected population, institutional capacities, social structures, physical infrastructure and built environment ("social vulnerability," a core component of resilience [6]). However, the underlying main contributing factors of social vulnerability in developing nations still remain inadequately characterized [7]. A better understanding of the interactions between landslide hazard and social vulnerability through the hazard chain is crucial for the enhancement of resilience. In addition, academic research on resilience has historically been poorly integrated with policy actors, planners, national governments and public understanding [8]. Based on the aforementioned observations and focusing on the data-rich, earthquake-prone Sichuan province, this paper addresses the following main research objectives: 
- Better characterize the physical mechanisms governing earthquake and rainfall-induced landslide hazard.

- Map the spatial-temporal variations in the vulnerability of the social and built environment across seismically active regions of Sichuan, and explore their relationship to seismic hazard and earthquake impacts.

- Create an early warning system for post-earthquake landslides, embedded within the 3D WebGIS-based Computational Urban Sustainability Platform (CUSP).

- Integrate science and policy via engagement with organizations that straddle the science-policy divide (boundary organizations), and through co-producing a model for analyzing earthquake resilience across Sichuan under various demographic and policy scenarios. To this regard, the Sichuan's earthquake resilience profile will be approached under several socioeconomic scenarios and policy interventions.

The high interdisciplinary nature of the research addresses several fields, such as geology, risk management, human geography, urban planning and civil engineering. It encompasses physical, social and engineering perspectives aiming at the development of resilience against earthquake related hazards. As a result of that, key beneficiaries have been identified both in policy and academic figures. Notably, the high-resolution spatial-temporal landslide dataset will represent a valuable resource for the earthquake community, since the maps and dataset resulting from the research will be distributed via open source software. Environmental risk scholar will also gain a better understanding of social vulnerability issues in developing nations thanks to the elaboration of operational measures suited to the Chinese context. Human geographers and planners will benefit from a better understating of the interplay between physical hazards, social and built environment vulnerability, and the impacts of this interaction on distributions of loss and recovery. Furthermore, the development of models and simulations will enable scholars involved in decisionmaking to provide an evidence based resilience design.

The paper first provides an overview of resilience in terms of its definition and existing academic frameworks, then a breakdown of the diverse working threads building up the research backbone will be provided. A description of the most significant key findings resulting from each stage of the research will be included and a final delineation of future work will be concluded in the paper.

\section{RELATION TO EXISTING THEORIES AND WORKS}

A background knowledge of previous relevant works has been considered key in order to develop a resilience framework. Hence a review of related literature has been carried out addressing both resilience from a broader point of view and then more focused on the built environment.

Given the multi-domain nature of resilience, various attempts have been taken to measure and define it from an interdisciplinary perspective. The etymology of the word, identified in the Latin verb "resilìre" meaning "to jump back" [9] provides a linkage with the engineering and physics domain, in which resilience denotes the ability of a material of absorbing energy while loaded in the elastic phase and then recovering when the load is removed [10]. Controversially, given its first application in the psychology and psychiatry field in the 1940s [10]-[12], resilience has been later approached in the Ecology domain by Holling [13] who provided a first linguistic distinction between resilience itself and the concept of stability in socio-ecological systems (SES).

According to Holling [14] resilient systems are able to respond positively to disturbances with large fluctuations, whereas stability consists in oscillations not too far from an equilibrium condition of the system. Holling introduced also the concept of "domains of attraction" applied to SES as the tendency of a system in reaching an equilibrium condition [13]. This theory has been later revised by Walker and colleagues who developed it into a more analytical formulation, devising resilience as the tendency of remaining in the same basin of attraction [15]. Folke [16] pointed out that a limit of the basin of attractions is the multiplicity of types of attractors, which can vary from points to entangled trajectories, hence a system could be attracted by conflicting conditions [16].

Moreover, variability can be identified as a feature of resilient systems, and has been effectively represented by the "adaptive cycle theory", stating that during their lifespan, SES go through four different phases: rapid growth and exploitation (r), conservation $(\mathrm{K})$, release and disruption $(\Omega)$ and eventually a recovery and reorganization phase $(\alpha)$ [17]-[19]. This multiplicity of state conditions during a system's lifespan has been identified also referring to networks in general and implementing the time component as well [20],[21]. Based on this multi-stage resilience process a mathematical formulation of resilience itself has been achieved developing an alternative graphic visualization of it [22].

One of the first qualitative resilience-addressed frameworks has been devised by Bruneau et al. [23] aiming at the improvement of the ability of communities to recover from natural hazards through the evaluation of the real system performance after being disrupted and its ideal non damaged condition [23]. They also stated the interconnection of the different domains to which resilience refers, in particular in relation to Technical, Organisational, Social and Economical (TOSE) factors; classifying also the four properties of resilience: resourcefulness, robustness, redundancy and rapidity. Cimellaro [24] achieved a more engineered formulation for resilience in the development of a metric that encompassed both the concept devised by Bruneau [23] and elements inherent from buildings' structural analysis [24].

Further research has been carried out dealing with earthquake-related geological issues, such as slow-moving earth slides, rock slides and debris flows, including also the implications for the built environment. In particular, several authors [25]-[27] focused on reinforced concrete (RC) framed structures, mainly because they are common in the worldwide building stock. Instead, the analysis to be carried out in this paper encompasses several structural typologies. In particular, a questionnaire has been devised and distributed in high-risk areas of the Sichuan Province in order to gather vulnerability and damage-related noteworthy information regarding both the built environment and the social impact of the disruptive event. The 
damage to buildings has been categorized by means of the identification of diverse degrees and typologies, adapting the damage scale proposed by Mavrouli [26], due to the specificity of the damage scale and that both structural and non-structural components have been taken into consideration.

As a result of the hazard-related review the most notable approaches are described, addressing the geo-environmental disruption categories mentioned before. Rock falls, for instance, have been modelled considering the probability of a rock hitting a structural element of a RC framed structure and through an iterative calculation new stable states for the overall building can be defined [27]. As far as the Wenchuan territory is concerned, an earthquake-triggered rock fall struck the city of Beichuan.

With regard to slow-moving earth slides their implications are visible in the long-run in terms of differential settlements on the foundation levels, which can lead to major structural damages in the superstructure. This issue has been approached by Uzielli et al. [28] with regard to a landslide event and its analysis addressing the vulnerability for a set of buildings in the area subjected to the hazard.

The impact of debris flows on the built environment in particular can be devastating given the intrinsic high-speed of the material moved over these events. To this regard, several attempts have been carried out to assess quantitatively how debris flow can affect the stability of infrastructures and buildings over time [29]. The approach proposed by Jakob [29] is noteworthy since it takes into account the most influencing factors both in terms of vulnerability and aftermath, hence damage conditions. In particular, their approach draws on a clear methodology that relies on a database of past debris flow events from which they have been able to gather relevant data about the hazard intensity, identification structural material and typology of the at risk element, but also velocity and sedimentation entity of the debris [29].

\section{RESEARCH METHODOLOGY}

The complex and multi-domain nature of the project requires a defined and structured organization of the activities expected to be adressed to achieve the project objectives. As a consequence, the project framework is devised into a number of inter-working research threads. Figure 1 provides a schematic overview of the project methodology. For the sake of clarity, given the high interconnectivity amongst the diverse working threads, only the linkages in the context of the present analysis have been highlighted.

\section{A. Analytical investigation on the mechanism of post- earthquake debris-flow and social-vulnerability}

The first working thread addresses both the understanding of the analyzed debris flow triggering mechanism and the development of an effective framework for the social vulnerability. With regard to this first phase, field observation and laboratory experimentation have been conducted with the aim of understanding the mechanisms behind post-earthquake debris flows events. Based on first observations made by the Chinese Partners, the landslide mechanism revealed some differences from the usual shallow-landslide model due to their recurrent origin in low- order drainage systems dammed by coseismic landslide debris. To this regard, it has been significant to evaluate the contribution of the damming to the debris flow triggering phenomenon. In order to reach this level of knowledge, 7 highly hazardous debris flow gullies are being monitored by means of rainfall, pore pressure, soil moisture sensors, video and both sonic and ultrasonic gauges. Moreover, the provision of terrestrial and aerial vehicles allows the collection of high-resolution and multi-temporal point clouds. In addition, geotechnical parameters such as material composition, grain size, density and hydrologic characteristics, are imperative given the multi-disciplinary nature of the project. Following the investigation procedure, laboratory experiments in a large-scale flume have been conducted aiming at the achievement of a better knowledge regarding the analyzed debris flow triggering mechanism.

An operational framework for social vulnerability in the Chinese context is being developed, involving key parameters including: socio-demographic factors, access to resources, social capital and cohesion, beliefs and customs, building stock and age, type and density of infrastructure and the community adaptation capability [6]. Social vulnerability frameworks exhibit their utility in enhancing resilience-building interventions in order to fix possible deficiencies, such as evacuation plans in case of disaster. As a starting point, a review of previous approaches towards social vulnerability has been deemed necessary to identify relevant correlations amongst natural hazards and community resilience. Object of review will be potential policy interventions aimed at the reduction of social vulnerability, but also the process through which social vulnerability itself might alter the ability of community to recover and adapt to disruptions.

\section{B. Risk and resilience spatial patterns governed by social vulnerability and landslide hazard}

The objective of the current stage consists in explaining spatial patterns of risk and resilience by improving temporal resolution of hazard mapping, starting with the quantification of the landsliding rate of several aftershocks and storms achieved through the development of a large data set. Even if landslides created by aftershocks and post-earthquake storms are supposed to generate large, post-earthquake river sediment yields, the understanding of the role of aftershocks and rainstorms is not evident, due to the low temporal resolution of landslide inventories. As a consequence, the project aims to improve the temporal resolution of the landslide dataset, including commercial high-resolution multispectral satellite imagery. Following to that, pre-2008 imagery will be adopted as a baseline to establish the initial landslide situation, by means of imagery that closely bracket large aftershocks or storm events.

The framework developed in the first working thread involved a spatial-temporal mapping analysis of social vulnerability across the Sichuan Province, using multiple scales in order to meet policy makers and planners' requirements. The maps resulting from the analysis has been embedded in the Chinese partners' WebGIS platform for risk assessment and communication, which turned out to be functional in order to achieve higher standards of emergency preparations, disaster response and long-term recovery.

Another aspect involves the investigation of the role of social vulnerability in softening the impacts of disasters, which has 

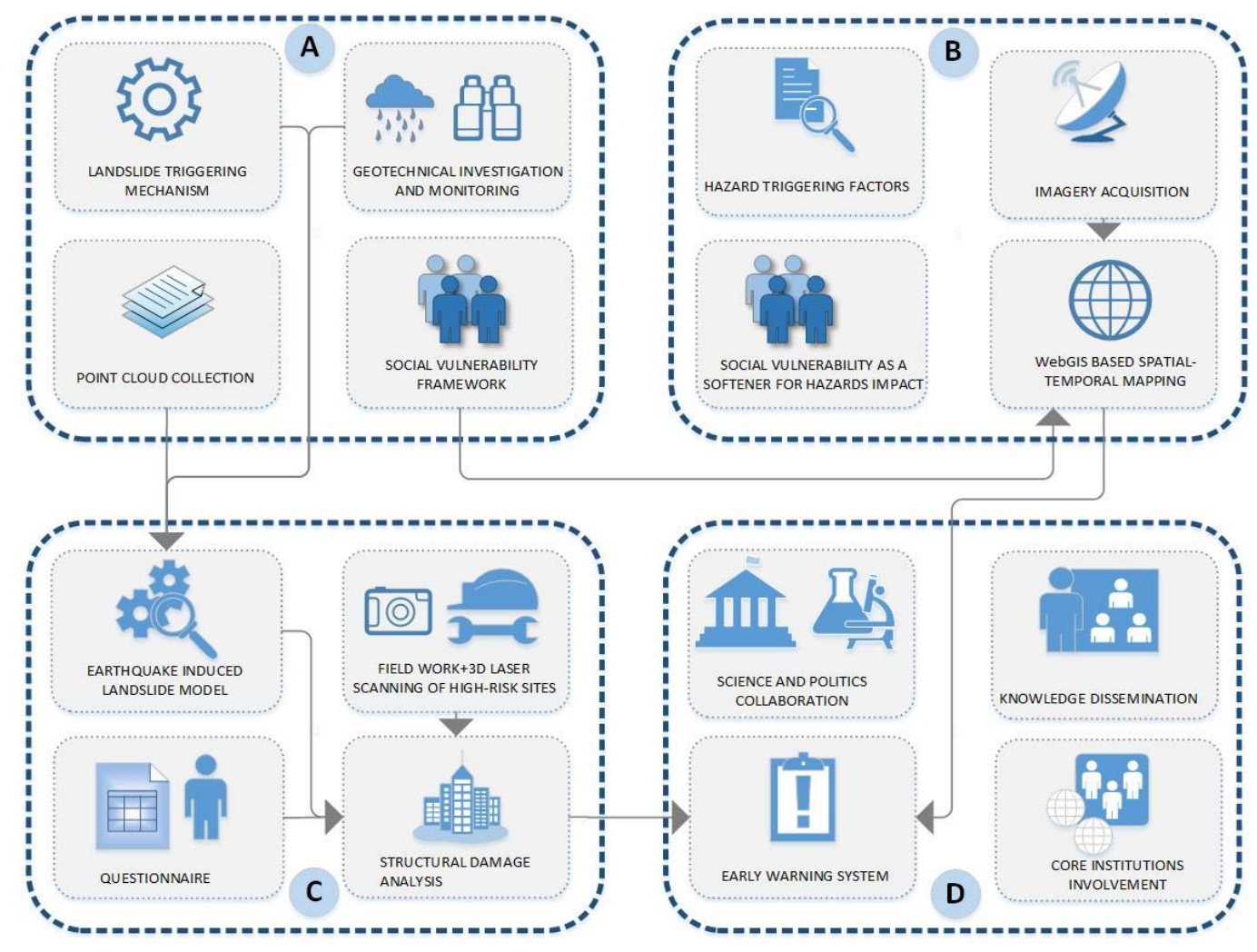

Figure 1: Project methodology workflow

been developed through the combination of explicit fatality dataset from the Wenchuan earthquake and subsequent events and socio-economic databases that can be representative of the vulnerability of the area. This has been achieved through the application of the developed framework for social vulnerability and the involvement of quantitative techniques (e.g. multivariate regression, geographically weighted regression and propensity score matching) in order to explain if the variance of fatalities due to the Wenchuan earthquake can be explained by social vulnerability. The analysis started at the aggregate level, then moved to the disaggregate level, which respectively represents the indicator for social vulnerability and the individual dimension of vulnerability. Next, the mechanistic point of view has been taken into account in order to consider also social cohesion, which consists in one dimension of social vulnerability [30], proven to play a consistent role as moderator for health and economic impacts of natural hazards [31]. Hence, social cohesion is an influencing factor in the development of the resilience of a place and should be supported by policymakers.

\section{Modelling resilience through the earthquake-induced landslide hazard chain}

In the course of this phase the focus involves the achievement of a spatial-temporal model of earthquake- and rainfall-induced landslide hazards that allows the understanding of the impact of aftershocks and rain events on landslides. Two different models of earthquake and rainfall induced landslides have been combined together with the aim of obtaining a probabilistic model of landslide applicable to different earthquake and rainfall scenarios and the implementation of the temporal distribution of landslide initiation will achieve the development of the spatial-temporal model. The model developed in order to estimate earthquake-induced landslides based on ground motion (from US Geological Survey Shakemap) topography and geology uses a logistic regression approach [32], whereas the second model addresses to rainfallinduced landslides by means of rainfall, geology and topography data [33]. Following on these steps, the material properties changes through the post-earthquake period have been included in the form of evidence collected during the field studies of the first working thread and high-resolution imagery resulting from the second one. The analysis have been accounting for the influence of rock fatigue damage accumulated in hillslopes from previous earthquakes in the sequence [32] and for the possible exhaustion of new hillslope material created by seismic shaking. The contribution to research in this particular context has been given due to the consideration of the rate at which new earthquake generated material is removed from hillslopes, achieved through the field observation and remotely sensed data.

A stage of the current working thread consisted also in the development of an early warning system for key monitored debris flow gullies, by means of the collection of critical rainfall intensities required to trigger debris flows which has been carried out in the first working package. The model is able to carry out predictions of debris flows depending on rainfall factor, taking into account antecedent rainfall and their intensity, topographic and geology factors and an empirical-derived critical threshold [33]. The outcome of this model consists in a relevant pathway with potential stakeholders, as devised in the 
fourth working thread. The data catchment area is going to provide the required warning threshold for seismic activity and related events in addition to be implemented in the Computational Urban Sustainability Platform (CUSP), a WebGIS-based graphical interface that has been adapted in order to provide straightforward decision-making capabilities for strengthening resilience in the Wenchuan area (Figure 2).

The issue addressing resilience in the built environment context will be also evaluated as part of third stage of the project, drawing on building information modelling (BIM) and GIS techniques to investigate building performance towards earthquake-triggered landslide scenarios. Based on the 2014 framework "Quantifying Sustainability in the Aftermath of Natural Disasters"[34] developed by the BRE Centre for Sustainable Engineering, a new proposal of resilience evaluation is currently under development, addressing both at micro (building level) and macro scale (city/regional scale). The current model for resilience is comprehensive of both external and internal factors respect to the built environment. With regard to the first category environmental indicators such as soil features, rainfall data and social vulnerability factors are implemented, whereas building-related properties are considered as internal factors. As a part of the current stage of the research, a survey has been devised in collaboration with the Chinese Partners and its dissemination has taken place in Nov/Dec 2016.

Further field work has been carried out to determine more specifically which kind of disruptions have affected the built environment in the context of seven different locations of the Wenchuan County. The latter included visiting relevant sites in which infrastructures have been developed in order to front geoenvironmental hazards, mainly different typologies of weirs built in order to dissipate the flow energy and in some cases separate different soil diameter size components as well. A more detailed mapping of both buildings and infrastructures was accomplished by means of 3D laser scanning techniques in the relevant sites affected by earthquake-triggered events in the Sichuan province. An example of this was the city of Beichuan, in which the combination of geophysical issues related to soil properties and earthquake features caused fatal disruptions to the building stock (Figures 3 and 4). Disruptions likely to result from a debris flow with high-diameter rocks was identified in Qipan Gully (Figures 5 and 6), in which structures have been significantly compromised.

The point clouds resulting from the $3 \mathrm{D}$ scanning field work are currently in course of elaboration by the Chinese Partners and after that a GIS mapping regarding the damage degree and typology will be developed. For the sake of coherence and ease of data elaboration the same damage scales and categories as mentioned in the questionnaire will be considered here.

\section{Connecting and overcoming the science - policy nexus}

The final working thread deals with overcoming the divide between science and policy institutions, achieved through the interactions with core organizations, in order to demonstrate the relevance of the model as an early-warning system for earthquake-triggered landslides and debris flows. Furthermore, since the final year of the project will mark the 10 year anniversary of the Wenchuan earthquake, educational materials in collaboration with cultural institutions will be produced.

\section{PRELIMINARY KEY FINDINGS}

This section summarizes the key findings resulting from the field work carried out in the period from $4^{\text {th }}$ to $20^{\text {th }}$ December 2016, with a focus on the third working thread. The point cloud data resulting from the 3D scanning activity are currently under elaboration. Despite the temporary lack of scanning data, the photographic material and field work observations allowed the achievement a qualitative categorization of the damage typologies with respect to the built environment as a result of an adequate structural diagnosis. As a matter of fact the damage state of a structure is able to provide relevant information about:

- Disruptive event intensity (e.g. magnitude, regarding earthquakes);

- Quality of the material employed for the structure (e.g. unsuitable positioning of bricks for load bearing walls structures or incorrect concrete mixture for RC buildings);

- Resilient abilities of the building;

- Soil conditions and rough consideration about its typology;

- Hypothesis about foundation type;

Following qualitative structural analysis mainly addressing buildings, some common causes have been identified as main factors contributing to the present disrupted condition. These elements include both external (e.g. soil properties) and internal (e.g. building features) factors with regard to buildings. In detail, amongst the external factors should be included the vertical component of Peak Ground Acceleration (PGA) exceeding the horizontal one in a not usual manner during the 2008 Wenchuan earthquake [1], [35]. Similarly, clear evidences of soil inconsistency and probable liquefaction as well have been qualitatively observed and included in the contributing factors. A lack of geotechnical investigation and proper intervention techniques planning has been registered, given the collapse mechanism registered in some buildings, involving differential settlements which were clear consequences of unsuitable foundation typologies. The latter element should be listed amongst the internal factors, as well as inadequate longitudinal and shear rebar percentages that require to be verified whether in accordance with the building regulations in force at the time of construction. In some visible column and 


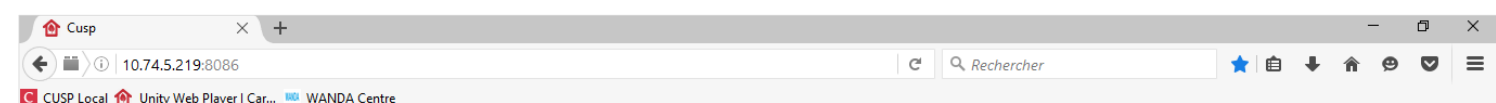

嗲 Computational Uriban Sustainability Plattorm
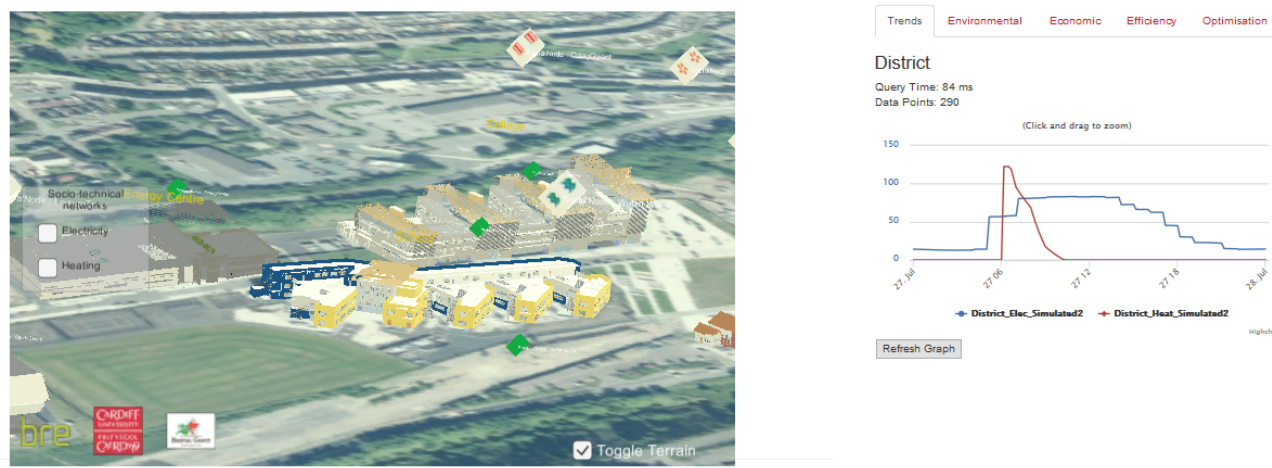

District

Query Time: $84 \mathrm{~ms}$
Data Points: 290
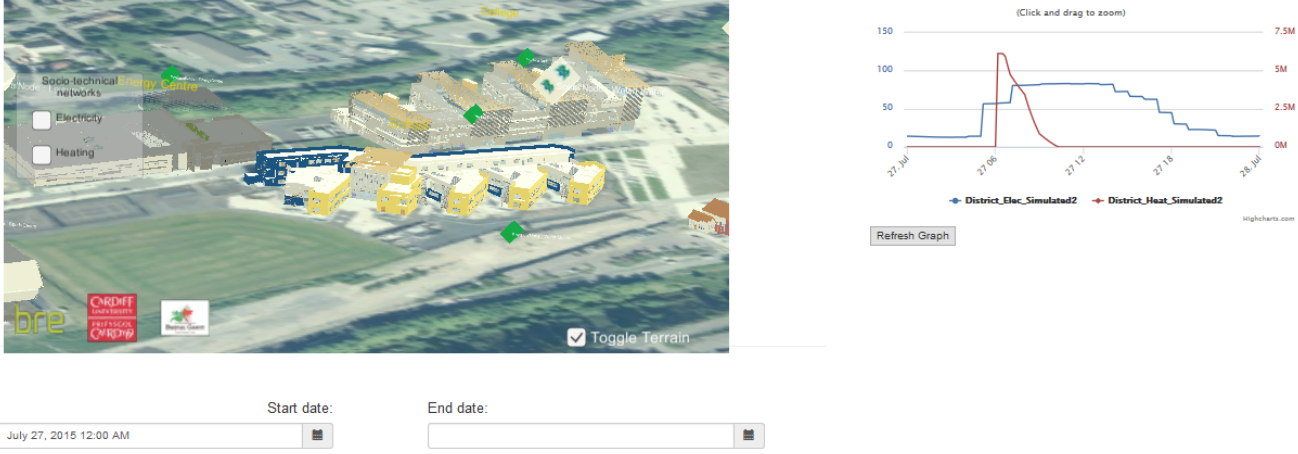

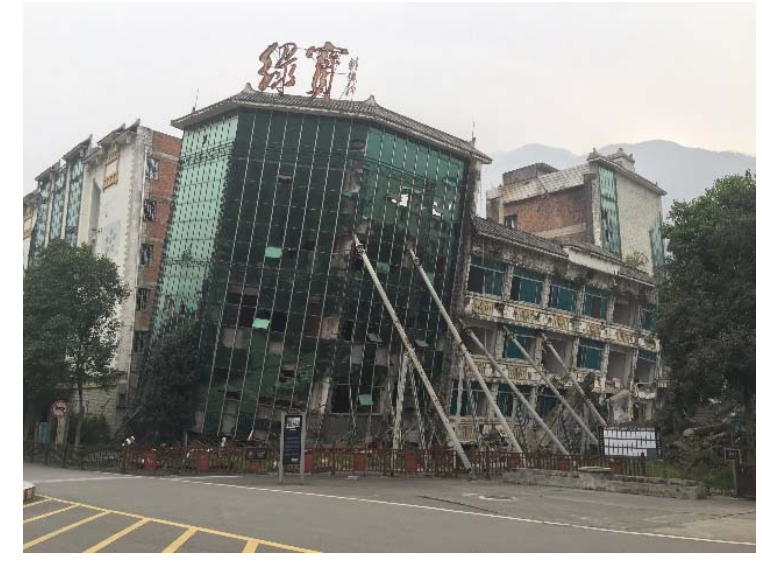

Figure 3: Lvbao Hotel in Beichuan

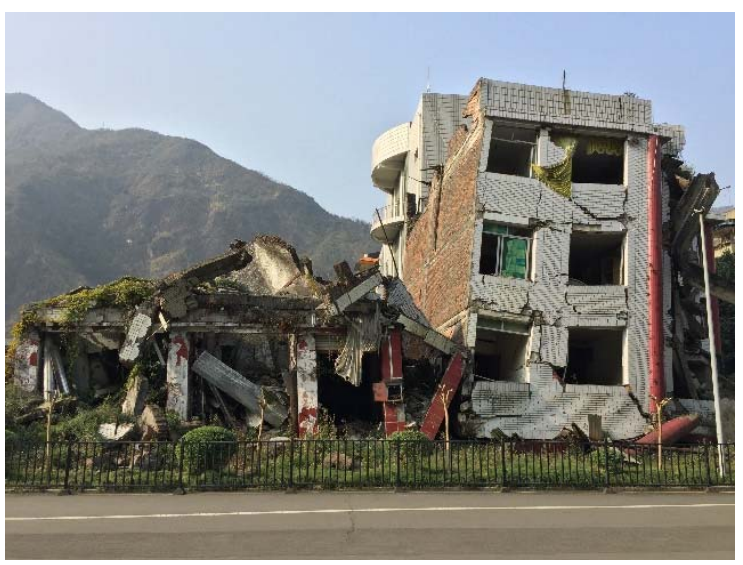

Figure 4: Example of soft-storey phenomenon in a building in Beichuan beam collapsed sections it has been possible to observe improper concrete mixture evidences, such as an excessive aggregate diameter.

With regard to building-related damages the county of Beichuan represented one of the most significant source of data, since the earthquake hit that area stronger than the nearby ones, given the city location on the edge of the surface rupture between Yingxiu and Beichuan [36], [35]. The earthquake triggered also an extensive rock fall in an adjacent mountain and this struck the city causing further damages to buildings. Qipan Gully (Figure 5 and 6) provided meaningful resources in terms of structural building damages as a consequence of what has been hypothesized to be a debris flow or a flow-type slide, compromising both the stability and functionality of the majority of the building stock present in the area.

Inadequate techniques have been employed as well in secondary roads leading to isolated buildings located in mountainous areas, representing a major threat since the soil underneath mainly consists of limestone and other lowresistance typologies. To this regard, unsuitable concrete mixtures have been spotted, as well as secondary roads realized by means of non-reinforced concrete slabs with no bases or stabilizing layer underneath. That means that in case of disruption vulnerable infrastructures might prevent people from leading to safe locations, putting at risk a higher number of lives or even obstruct emergency services access.

Meanwhile, it is seen that high impact geotechnical interventions have been made in order to soften or prevent the effects of geo-environmental hazards. These mainly consist of weirs and slope reinforcement measures, such as concrete grids (Figure 7). The latter though appear to be inefficient because mainly pertaining small portions of entire at risk slopes. The drawback regarding weirs consists in their regular need for 


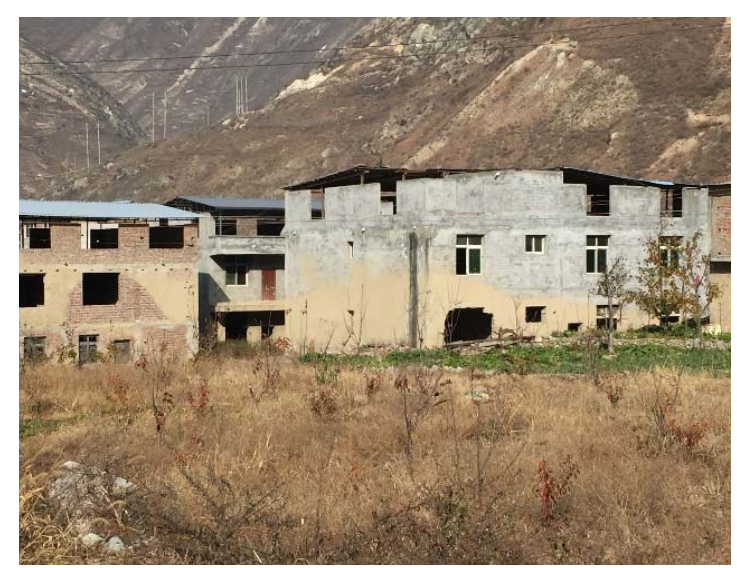

Figure 5: Flow-type slide damage on buildings in Qipan Gully

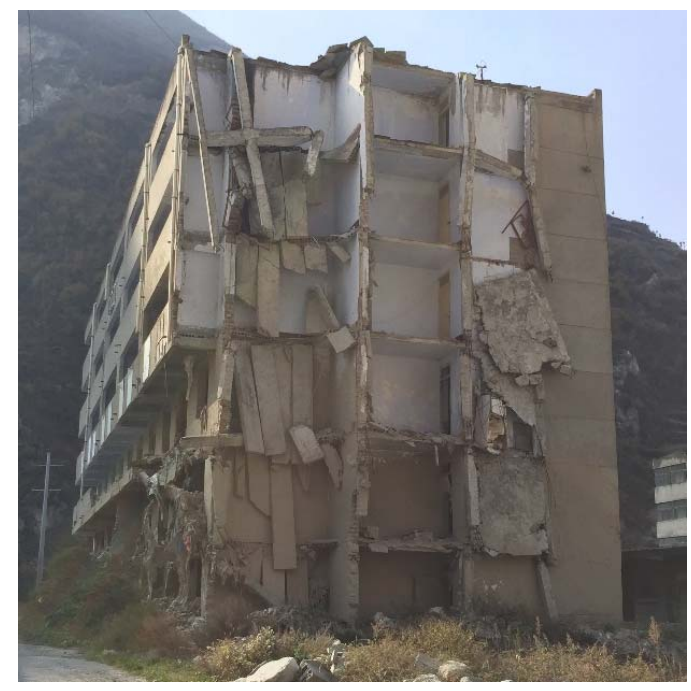

Figure 6: Flow-type slide damage in Qipan gully to a residential building

maintenance in terms of debris removal in the upstream section, otherwise their functionality might not be guaranteed.

\section{CONCLUSIONS}

The present paper aimed at describing the overall methodology employed in order to tackle the issue regarding low resilient environments subjected to geo-environmental hazards, in particular seismic triggered phenomena after the 2008 Wenchuan earthquake in the Chinese Sichuan province. For the purpose of this analysis the focus is put on the built environment analysis, but from a broader viewpoint resilience is approached with a multi-objective perspective embedding engineering and technical related issues with social vulnerability $[37,38]$.

The Wenchuan territory is undoubtedly subjected to major geo-environmental hazards of strong intensity, such as earthquakes and different typologies of landslide. The preventive measures employed till the present moment are clearly not sufficient to soften the impact of the aforementioned disasters. Some stronger and more impacting interventions have been implemented but there is an urgent need for more

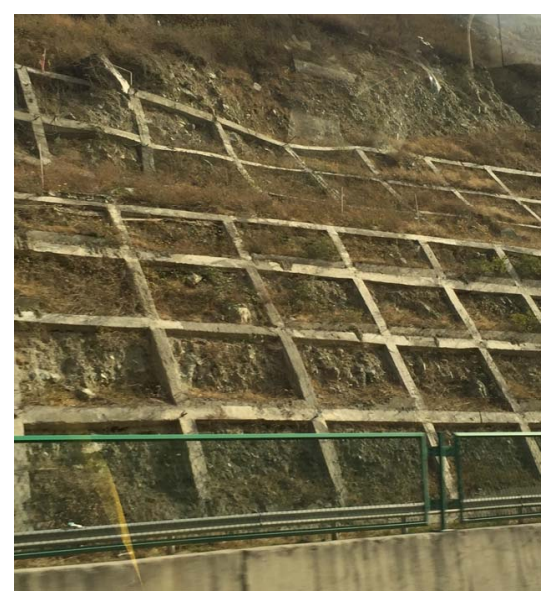

Figure 7: Concrete grids as a slope stabilization intervention

geotechnical, site-specific and hazard-focused design measures, able to take into account all the significant factors that can lead to major disasters.

The fruitful field work that took place in the Sichuan province in December 2016 allowed to gather high relevance data related to the built environment state of art and information regarding the pre-disruption conditions which will lead to a specific structural and georeferenced based analysis. Following to that, the point clouds resulting from the $3 \mathrm{~d}$ laser scanning will be merged together with the structural analysis in order to achieve a geometrical model of the disrupted areas allowing an easier categorization of the damage typologies. Thanks to the previous activities a more effective development of resilient measure towards disruptions will be achieved in the future.

All in all the Chinese experience following to the 2008 Wenchuan Earthquake is teaching an important lesson about wrong construction practices and pushes for a change in the future preliminary analysis to be conducted before proceeding to construction. Specifically, more attention should be paid to geologically related assessments and it should be necessary for building regulations to include specific soil evaluations of the area destined to host urban districts or infrastructures. In addition to that, a stricter control should be put on the construction chain related to the material production (e.g., concrete mixture production). However, it still needs to be verified if some of the identified faults were in accordance to the building regulations valid at the time of construction. Thus, strong measures ought to be adopted in order to enhance and sensitize designers and other figures related to the building design process about adopting a more holistic approach able to consider the construction in its entirety and its linkages with the surrounding context, especially in geo-environmental hazard prone areas, such as the ones analyzed in this research.

\section{REFERENCES}

[1] X. Li et al., "Strong motion observations and recordings from the great Wenchuan Earthquake," Earthq. Eng. Eng. Vib., vol. 7, no. 3, pp. 235-246, Sep. 2008.

[2] T. Gorum et al., "Distribution pattern of earthquake-induced landslides triggered by the 12 May 2008 Wenchuan earthquake," Geomorphology, vol. 133, no. 3-4, pp. 152-167, Oct. 2011. Z. Wang, "A preliminary report on the Great Wenchuan Earthquake," 

2013.

[5] United Nations, "Sendai Framework for Disaster Risk Reduction 2015-2030," 2015.

[6] S. L. Cutter, B. J. Boruff, and W. L. Shirley, "Social Vulnerability to Environmental Hazards*," Soc. Sci. Q., vol. 84, no. 2, pp. 242-261, Jun. 2003.

[7] W. Chen, S. L. Cutter, C. T. Emrich, and P. Shi, "Measuring social vulnerability to natural hazards in the Yangtze River Delta region, China," Int. J. Disaster Risk Sci., vol. 4, no. 4, pp. 169-181, Dec. 2013.

[8] M. Gall, K. H. Nguyen, and S. L. Cutter, "Integrated research on disaster risk: Is it really integrated?," Int. J. Disaster Risk Reduct., vol. 12, pp. 255-267, Jun. 2015.

[9] R. J. T. Klein, R. J. Nicholls, and F. Thomalla, "Resilience to natural hazards: How useful is this concept?," Environ. Hazards, vol. 5, no. 1, pp. 35-45, Jan. 2003.

[10] G. P. Cimellaro, C. Fumo, A. M. Reinhorn, and M. Bruneau, Technical Report MCEER-09-0009, "Quantification of Disaster Resilience of Health Care Facilities," Buffalo, NY, USA, 2009

[11] S. B. Manyena, "The concept of resilience revisited," Disasters, vol. 30, no. 4, pp. 434-450, 2006.

[12] M. a Waller, "Resilience in ecosystemic context: evolution of the concept," Am. J. Orthopsychiatry, vol. 71, no. 3, p. 290-297 (p. 291), 2001

[13] C. S. Holling, "Resilience and Stability of Ecological Systems," Annu. Rev. Ecol. Syst., vol. 4, no. 1, pp. 1-23, 1973.

[14] C. S. Holling, D. W. Schindler, B. W. Walker, and J. Roughgarden, "Biodiversity in the functioning of ecosystems; an ecological synthesis.," in Biodiversity loss: economic and ecological issues, Cambridge: Cambridge University Press, 1995, pp. 44-83.

[15] B. Walker, C. S. Holling, S. R. Carpenter, and A. P. Kinzig, "Resilience, Adaptability and Transformability in Social-ecological Systems," Ecol. Soc., vol. 9, no. 2, p. art5, 2004.

[16] C. Folke, S. R. Carpenter, B. Walker, M. Scheffer, T. Chapin, and J. Rockström, "Resilience Thinking: Integrating Resilience, Adaptability and Transformability," Ecol. Soc., vol. 15, no. 4, 2010.

[17] C. S. Holling, "The resilience of terrestrial ecosystems: local surprise and global change," in Sustainable development of the biosphere, W. . Clarkland and R. E. Munn, Eds. Cambridge: Cambridge University Press, 1986, pp. 292-317.

[18] L. Gunderson and C. S. Holling, Panarchy: understanding tranformations in human and natural systems. Washington, DC: Island Press, 2002.

[19] S. Carpenter, B. Walker, J. M. Anderies, and N. Abel, "From Metaphor to Measurement: Resilience of What to What?,' Ecosystems, vol. 4, no. 8, pp. 765-781, Dec. 2001.

[20] D. Henry and J. Emmanuel Ramirez-Marquez, "Generic metrics and quantitative approaches for system resilience as a function of time," Reliab. Eng. Syst. Saf., vol. 99, pp. 114-122, 2012.

[21] M. Ouyang and L. Dueñas-Osorio, "Time-dependent resilience assessment and improvement of urban infrastructure systems," Chaos An Interdiscip. J. Nonlinear Sci., vol. 22, no. 3, p. 33122, 2012.

[22] D. Gama Dessavre, J. E. Ramirez-Marquez, and K. Barker, "Multidimensional approach to complex system resilience analysis," Reliab. Eng. Syst. Saf., vol. 149, pp. 34-43, 2016.

[23] M. Bruneau et al., "A Framework to Quantitatively Assess and Enhance the Seismic Resilience of Communities," Earthq. Spectra, vol. 19 , no. 4, pp. 733-752, Nov. 2003.

[24] G. P. Cimellaro, A. M. Reinhorn, and M. Bruneau, "Framework for analytical quantification of disaster resilience," Eng. Struct., vol. 32 , no. 11, pp. 3639-3649, Nov. 2010.

[25] F. Parisi, C. Galasso, and G. Sabella, "Fragility of reinforced concrete framed structures to flow-type landslides," in 12th International Conference on Applications of Statistics and Probability in Civil Engineering (ICASP12), 2015.

[26] O. Mavrouli et al., "Vulnerability assessment for reinforced concrete buildings exposed to landslides," Bull. Eng. Geol. Environ., vol. 73, no. 2, pp. 265-289, 2014.

[27] O. Mavrouli and J. Corominas, "Rockfall vulnerability assessment for reinforced concrete buildings," Nat. Hazards Earth Syst. Sci., vol.
10, pp. 2055-2066, 2010.

[28] M. Uzielli, F. Catani, V. Tofani, and N. Casagli, "Risk analysis for the Ancona landslide---II: estimation of risk to buildings," Landslides, vol. 12, no. 1, pp. 83-100, 2015.

[29] M. Jakob, D. Stein, and M. Ulmi, "Vulnerability of buildings to debris flow impact," Nat. Hazards, vol. 60, no. 2, pp. 241-261, 2012.

[30] D. P. Aldrich and Y. Sawada, "The physical and social determinants of mortality in the 3.11 tsunami," Soc. Sci. Med., vol. 124, pp. 66-75, Jan. 2015.

[31] R. J. Samson, "When disaster strikes, it's survival of the sociable," New Sci., 2013.

[32] R. N. Parker, G. T. Hancox, D. N. Petley, C. I. Massey, A. L. Densmore, and N. J. Rosser, "Spatial distributions of earthquakeinduced landslides and hillslope preconditioning in the northwest South Island, New Zealand," Earth Surf. Dynam, vol. 3, pp. 501-525, 2015

[33] B. Yu et al., "A prediction model for debris flows triggered by a runoff-induced mechanism," Nat. Hazards, vol. 74, no. 2, pp. 11411161, Nov. 2014

[34] BRE, "Quantifying Sustainability in the Aftermath of Natural Disasters," 2014.

[35] F. C. Dai, C. Xu, X. Yao, L. Xu, X. B. Tu, and Q. M. Gong, "Spatial distribution of landslides triggered by the $2008 \mathrm{Ms} 8.0$ Wenchuan earthquake, China," J. Asian Earth Sci., vol. 40, no. 4, pp. 883-895, 2011.

[36] G. Li, A. J. West, A. L. Densmore, Z. Jin, R. N. Parker, and R. G. Hilton, "Seismic mountain building: Landslides associated with the 2008 Wenchuan earthquake in the context of a generalized model for earthquake volume balance," Geochemistry, Geophys. Geosystems, vol. 15 , no. 4, pp. 833-844, Apr. 2014

[37] Y. Rezgui, T. Beach, O. Rana, "Semantic and Holonic Multi-Agent Management of Distributed Energy Resources: Towards the Next Generation of Energy Systems," Jourbal of Civil Engineering and Management, vol.19, issue 2, pp. 239-258, 2013.

[38] M. Wetherill, Y. Rezgui, S. Boddy, G.S. Cooper, "Intra- and interorganizational knowledge services to promote informed sustainability practices," Journal of Computing in Civil Engineering, vol. 21, issue 2, pp 78-89, 2007. 